\title{
A compilation and meta-analysis of rainfall simulation data on arable soils
}

\author{
P. Fiener $^{\mathrm{a}, \mathrm{b}, *}$, S.P. Seibert ${ }^{\mathrm{c}}$, K. Auerswald $^{\mathrm{d}}$ \\ ${ }^{a}$ Geographisches Institut, Universität zu Köln, Albertus Magnus Platz, 50923 Köln, Germany \\ ${ }^{\mathrm{b}}$ Indo-German Centre of Sustainability, Indian Institute of Technology Madras, Chennai 600 036, India \\ ${ }^{\mathrm{c}}$ Institut für Hydrologie, Karlsruher Institut für Technologie, Kaiserstraße 12, 76131 Karlsruhe, Germany \\ ${ }^{\mathrm{d}}$ Lehrstuhl für Grünlandlehre, Technische Universität München, Alte Akademie 12, 85350 Freising-Weihenstephan, Germany
}

\section{A R T I C L E I N F O}

\section{Article history:}

Received 17 May 2011

Received in revised form 11 August 2011

Accepted 15 August 2011

Available online 23 August 2011

This manuscript was handled by Geof Syme,

Editor-in-Chief

\section{Keywords:}

Surface runoff

Rainfall simulations

Plot experiments

Arable land

Crust formation

\begin{abstract}
S U M M A R Y
Rainfall simulations are a useful and important tool in studying infiltration, surface runoff generation, soil erosion and nutrient as well as agro-chemical transport from arable land. Such simulations are time-consuming and costly and hence are usually only carried out under a limited variation of settings necessary to answer specific research questions. Therefore, it is difficult to use rainfall simulation data for hypothesis testing in a more general sense or to parameterize hydrological or erosion models applicable under a wider range of environmental conditions. To overcome these restrictions and to set-up a broader basis for following up studies, we analyzed, harmonized and filled gaps of a large set of existing rainfall simulations carried out by five different research groups in Germany. This covered 726 rainfall simulations (24,384 runoff measurements) carried out on 209 plots under a wide range of conditions for which 4 rain properties, 5 plot properties, 20 soil properties, 5 land use properties and 2 runoff properties were compiled. These data were quality controlled and made available for public use (Seibert et al., 2011). The most important deficiencies were smoothed runoff measurements, missing time to ponding data, different soil descriptions including frequent gaps in stone content, inconsistent moisture measurements and sometimes rather rough measurements of surface cover. The calculation of the geometric mean particle diameter, time since tillage and the application of different site specific procedures supported harmonization and helped to overcome several of these deficiencies. A satisfying gap filling procedure was developed for time to ponding. The most important inconsistencies that could not be removed were different depths of moisture measurement. Hence, there is a need to define a set of basic variables that always should be measured and documented with defined standards to enable comparison between different studies, to assess the boundary conditions of validity and possibly to make wider use of individual data sets by combining several of them.
\end{abstract}

(c) 2011 Elsevier B.V. All rights reserved.

\section{Introduction}

Surface runoff may cause erosion and muddy floods (Evrard et al., 2008), transport sediments, nutrients and pesticides to surface water bodies (Haygarth et al., 2006) and decrease yields (Lal, 2001) and ground water recharge (Fiener and Auerswald, 2003) due to a reduced infiltration. This is especially true for arable land and sparsely covered soils that are susceptible to crusting when exposed to rainfall (Assouline and Mualem, 2006; Le Bissonnais et al., 2005).

Rainfall simulation experiments are an important and common tool to study surface runoff generation (Adams et al., 2005; Meyer, 1960), soil erosion (Arnaez et al., 2007; Auerswald et al., 1994;

\footnotetext{
* Corresponding author at: Geographisches Institut, Universität zu Köln, Albertus Magnus Platz, 50923 Köln, Germany. Tel.: +49 221470 7802; fax: +49 221470 5124.

E-mail address: peter.fiener@uni-koeln.de (P. Fiener).
}

Bryan, 1970) and nutrient as well as agro-chemical transport from arable land (Baker et al., 1978; Volf et al., 2007). Compared to plots exposed to natural rain these experiments offer the advantage of high data quality and resolution under well defined conditions. This is especially true regarding rain properties, which usually are hold constant within one data set to facilitate comparisons between other treatments, which commonly are difficult to compare under natural rain conditions that may vary even on short distances (Fiener and Auerswald, 2009) and contribute to the variability between replicated plots under natural rain. Such replicated plots may vary in soil loss by a factor of two and more (Nearing, 1998; Nearing et al., 1999).

Rainfall simulations deliver discrete data about surface runoff and thus about the infiltration process. Individual research groups usually cover only a limited variation of settings (soils, management, rainfall properties, etc.) necessary to answer specific research questions as these experiments are time-consuming and costly. For the same reason the number of replicates is usually 
small and mostly within the spatial range of autocorrelation and thus must be regarded senso stricto as pseudo-replicates (Hurlbert, 1984). Both, the problem of restricted rainfall, soil and land management conditions tested and the problem of uncertainties in data of a small number of experiments, can be overcome to enlarge the benefits of rainfall simulations by compiling, harmonizing and analyzing data sets originating from different researchers.

The major goal of this study was to create such a compiled data set representing a large experimental and site variation under temperate conditions that can be used by other researchers to examine specific questions. To reach this goal (i) basic transfer functions to estimate important parameters not measured during all experiments had to be developed, tested and applied, and (ii) uncertainties in measured, homogenized and gap-filled data had to be estimated.

A striking observation during the compilation was that the different groups used different methods and measured different variables, which makes it almost impossible to compare results from different groups and to combine data sets for a meta-analysis to overcome the restrictions of the individual data sets. Some of these inconsistencies and lacking values could be overcome to some degree by homogenization and the basic transfer functions developed here. Still, there is an urgent need of a set of basic variables that always should be measured and a need of standards of how should be measured and documented to allow comparing results between rainfall simulation studies or to use their data in meta-analyses. In this respect our freely available data base (Seibert et al., 2011) may also encourage some standardisation.

\section{Material and methods}

\subsection{Terminology}

The runoff was always measured as accumulated runoff during a rainfall simulation. These measurements, which included also the measurement of time, will be called runoff measurements ( $n=24,384)$. They resulted from 726 simulated rain events, which we call runs. One to three runs were applied to the same plot within less than $48 \mathrm{~h}$. Such a combination of runs on the same plot will be called sequence $(n=370)$. The runs within a sequence are named according to the time span to the preceding simulated rain. Sequences start with a dry run $(n=336)$, which is the first simulation on a plot or a simulation following a preceding one after a time span much larger than $48 \mathrm{~h}$. Although this denotation is commonly used, it is misleading, because a dry run may be on a soil, which is wet due to natural precipitation. A run following more than $12 \mathrm{~h}$ and less than $48 \mathrm{~h}$ after the preceding run is a wet run $(n=126)$.

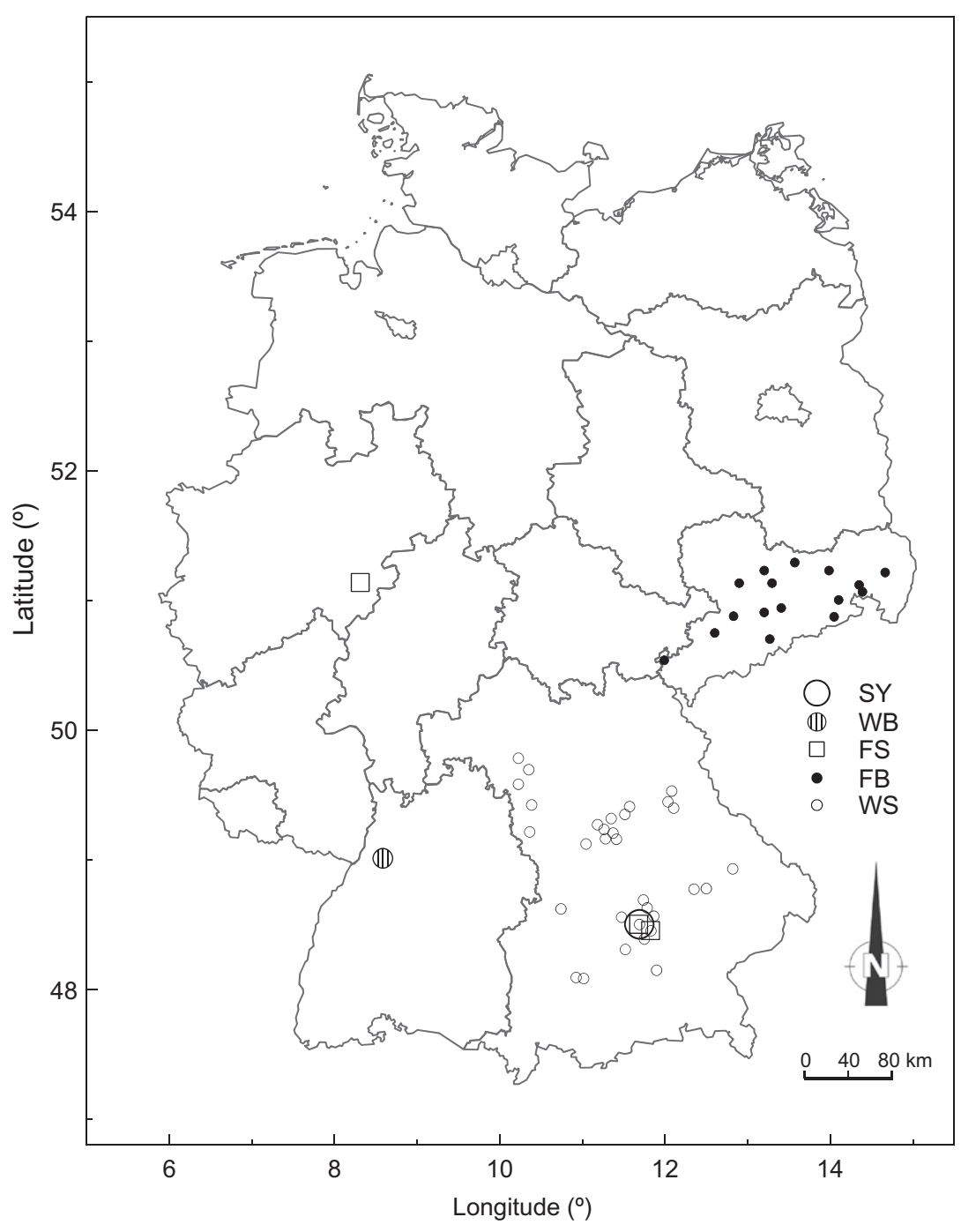

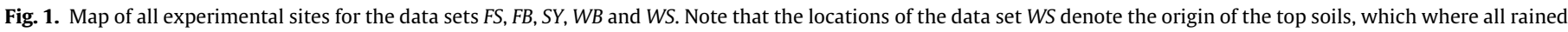
at one location (near SY) after long-term bare fallow. Lines show boundaries of the German federal states. 
Table 1

Land use, rainfall, geology and soil characteristics of the different test sites where the rainfall simulations were carried out.

\begin{tabular}{|c|c|c|c|c|}
\hline & Land use & $\begin{array}{l}\text { Mean annual } \\
\text { rainfall }\end{array}$ & Dominant geology & Dominant soils (IUSS Working Group WRB 2006) \\
\hline$F B$ & Arable & $600-1000$ & Loess, felsic magmatites and metamorphites & Eutric cambisols, stagnic and haplic luvisols \\
\hline FS & Arable & $850-1180$ & Loess, tertiary sediments and slate debris & Eutric and leptic cambisols \\
\hline SY & Arable & 850 & Loess, tertiary sediments & Stagnic and eutric cambisols \\
\hline$W B$ & Arable & 790 & Loess & Haplic luvisol \\
\hline WS & Long-term bare fallow & $550-1200$ & $\begin{array}{l}\text { Sand dunes, moraines, loess, tertiary sediments, } \\
\text { mesozoic sediments, basement rocks }\end{array}$ & $\begin{array}{l}\text { Leptic, vertic, stagnic, calcaric, } \\
\text { and eutric cambisols, luvisols }\end{array}$ \\
\hline All data & & $550-1200$ & - & - \\
\hline
\end{tabular}

Table 2

Rainfall and plot properties during the different rainfall simulations evaluated.

\begin{tabular}{|c|c|c|c|c|c|c|c|}
\hline \multirow[t]{2}{*}{ Study site } & \multirow{2}{*}{$\begin{array}{l}\text { Soils } \\
n\end{array}$} & \multirow{2}{*}{$\begin{array}{l}\text { Runs } \\
n\end{array}$} & \multicolumn{3}{|c|}{ Rainfall properties } & \multicolumn{2}{|c|}{ Plot properties } \\
\hline & & & $\begin{array}{l}\text { Intensity } \\
\left(\mathrm{mm} \mathrm{h}^{-1}\right)\end{array}$ & $\begin{array}{l}\text { Duration without afterflow } \\
\text { (s) }\end{array}$ & $\begin{array}{l}\text { Spec. kin. energy } \\
\left(\mathrm{J} \mathrm{m}^{2} \mathrm{~mm}^{1}\right)\end{array}$ & $\begin{array}{l}\text { Size } \\
\left(\mathrm{m}^{2}\right)\end{array}$ & $\begin{array}{l}\text { Slope } \\
(\%)\end{array}$ \\
\hline$F B$ & 43 & 77 & $31 \ldots 56$ & $1380 \ldots 6180$ & 20 & 44 & $6 \ldots 18$ \\
\hline$F S$ & 47 & 86 & $29 \ldots 99$ & $590 \ldots 3626$ & 20 & 7 & $9 \ldots 20$ \\
\hline SY & 57 & 111 & $58 \ldots 74$ & $1605 \ldots 3807$ & 20 & $6 \ldots 7$ & $2 \ldots 24$ \\
\hline$W B$ & 30 & 30 & $34 \ldots 65$ & $2892 \ldots 5940$ & 20 & 24 & $9 \ldots 18$ \\
\hline WS & 32 & 422 & $41 \ldots 80$ & $723 \ldots 3603$ & $12 \ldots 20$ & 8 & $8 \ldots 10$ \\
\hline All data & 209 & 726 & $29 \ldots 99$ & $590 \ldots 6180$ & $12 \ldots 20$ & $6 \ldots 44$ & $2 \ldots 24$ \\
\hline
\end{tabular}

Again this term is conventionally used but it has to be noted that it ignores that the most consistent difference compared to a dry run is not the difference in soil moisture but the existence of erosion features like surface sealing or rills resulting from a preceding extraordinarily large erosive rain. A run following after less than $12 \mathrm{~h}$ was called very wet run $(n=264)$ and can be preceded by either a dry run or a wet run. In general, a sequence can consist of a dry run only or any combination starting with a dry run, except for some rare cases $(n=34)$ where the dry run was discarded due to equipment failure. In several cases of bare-fallow plots rains followed on the same plot with a rain spell of several months and soil tillage in between. Hence the number of rained plots $(n=209)$ is smaller than the number of sequences.

\subsection{Origin of data sets}

The data base created in this study compiles five data sets from different regions in Germany (Fig. 1). The compilation simultaneously covers the results of several research groups, different site-characteristics (Table 1), and different rainfall simulators using different nozzles, intensities (Table 2) and measuring protocols, which are briefly described below. More information on these data sets can be found in the cited references.

\subsubsection{WS data set}

The largest data set WS with 422 rainfall experiments originates from Martin (1988). Experiments were carried out on 32 different arable top soils (Table 1 ) ranging from sandy to clayey with different stone contents. The soils were taken to one location from different landscapes (location of origin see Fig. 1) with different geological and climatic characteristics (Table 2). The intention of Martin (1988) was to cover the full range of topsoil properties found on arable land within a region of approximately $100,000 \mathrm{~km}^{2}$. More information about the soil properties can be found in Martin (1988) and Auerswald et al. (1996). The plots were kept under long-term bare fallow, which should allow identifying effects of different soils even though the soils differed in cultivation history. Seed bed was prepared manually a few days before the rainfall experiments. All 32 plots had a size of $8 \mathrm{~m}^{2}$ and a slope between $8 \%$ and $10 \%$ (Table 2). A Swanson-type rainfall simulator
(Swanson, 1965) modified by Auerswald (1986) with two different nozzles (Veejet 80100 and 8070) differing in drop size distribution and kinetic energy per unit of rain was used for the simulations (Table 2 and Fig. 2). Rainfall was simulated in different seasons throughout the years from 1985 to 1987. In most cases a sequence of three runs (dry, wet, and very wet) was applied.

\subsubsection{SY data set}

The data set SY was created by Schröder and Auerswald (2000) and comprises 111 simulations. It includes data from 57 different plots mainly representing stagnic and eutric cambisols (according to the system by IUSS Working Group WRB (2006)) developed on loess and partly tertiary sediments (Table 1 ). The soils were tilled after small grain harvest, residues were removed and a seedbed was prepared immediately before each dry rainfall run on a plot to have identical land use conditions. The main intention was to determine differences in crusting and hence infiltration for different soil types. Stone, residue and plant cover measurements are available for all 111 runs. Plot size varied between 6 and $7 \mathrm{~m}^{2}$, with

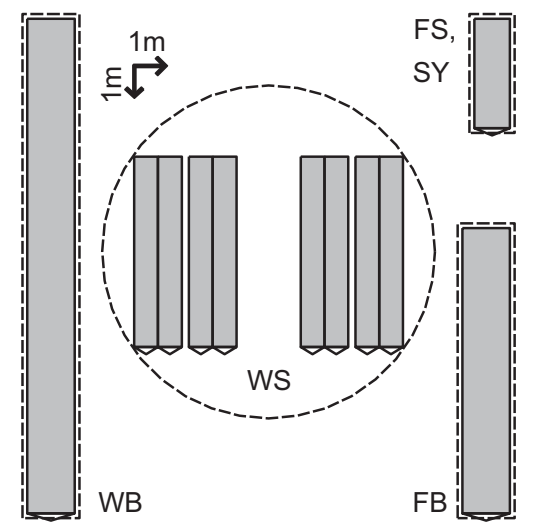

Fig. 2. Typical plot layout for the six data sets; the dotted line represents the rained area, the gray shaded area is the plot and the white triangle is the rain shielded gutter collecting the runoff. Eight plots were simultaneously rained under a rotating-boom rainfall simulator for the WS data set while rectangular simulators slightly larger than the plot size were used for the other data sets. 
slope gradients between $2 \%$ and $24 \%$ (Warren et al., 2004). A Kainztype rainfall simulator, which is a rectangular (Fig. 2), variableintensity simulator based on the Veejet 80100 nozzle (Kainz et al., 1992), was used in a sequence of two runs, where the dry run lasted for $60 \mathrm{~min}$ and was followed after $15 \mathrm{~min}$ by a very wet run for $30 \mathrm{~min}$.

\subsubsection{FS data set}

The data set FS originates from Haider and Auerswald (Auerswald and Haider, 1996; Haider, 1994). Overall the data set comprises 86 simulations. It represents 47 different eutric to leptic cambisols, according to the system by IUSS Working Group WRB (2006), developed on loess, tertiary sediments and slate (Table 1) found at three locations (Fig. 1). The soils at one location (Schmallenberg), developed from Devonian slate debris were the stoniest ones (up to 63\% stones) of the entire data set. All plots were tilled at least one month before the experiments. At one location successive experiments were carried out after planting barley (Hordeum vulgare), thus representing the effects of increasing plant cover. These plots had paired plots without cover that were rained as well. Following the main intention of the experiments to study the mechanisms, risks and consequences of herbicide transport into surface water bodies due to surface runoff and erosion under different arable conditions the pairs thus allow separating the effects of increasing plant cover and increasing time since tillage. The simulations, except for the location Schmallenberg, were carried out on soils, which were already included in the data sets WS and SY but the research groups differed. Plot sizes were $7 \mathrm{~m}^{2}$ with slopes ranging between $9 \%$ and $20 \%$. The same rainfall simulator as for the SY data set was used in sequences of two runs (Fig. 2). The dry one lasted $60 \mathrm{~min}$, the following very wet run lasted $30 \mathrm{~min}$. Both were separated by time span of $15 \mathrm{~min}$. Simulations were carried out under a wide range of intensities. Thus, by combining WS, SY and FS the four reasons for a varying effective kinetic energy - rain amount, rain intensity, drop size distribution (Table 2) and soil cover - were all modified independently.

\subsubsection{WB data set}

Thirty simulations taken from Gerlinger (1997) were included in the WB data set. Soils were haplic luvisols (IUSS Working Group WRB, 2006) mainly developed on loess (Table 1 ) with a predominantly silty texture (69-82\%). The data set included arable fields from different farmers with various crops and growth stages (e.g. plant cover 4-95\%) located within one catchment (Fig. 1). Moreover, time between simulations and preceding soil management operations varied between 0.5 and 66 days. Hence, it was possible to investigate spatial and temporal variability of erodibility, including the combined effect of soil and crop. Gerlinger (1997) applied rainfall on $24 \mathrm{~m}^{2}$ large plots with slopes between $9 \%$ and $18 \%$ (Table 2). In $W B$ rainfall was also applied with a Kainz-type simulator from the same manufacturer (ERTI, Munich, Germany) but with a plot length of $12 \mathrm{~m}$ (Fig. 2; Schramm, 1994). Only one rain was applied per plot but rainfall duration was not predetermined as in the other data sets but continued until steady-state runoff was reached.

\subsubsection{FB data set}

The data set $F B$ comprises 77 simulations (Michael, 2001). The 43 plots covered a large range of different soils (Table 1 ) with textures ranging from very sandy to very silty. The data set is comparable to the $W B$ data set as is covers the full range of cover (1-90\%, photometric determination prior the dry run), slope (6-18\%), time since last soil tillage operation (3-227 days) and initial volumetric soil moisture conditions (15-44\% in plough horizon). The experiments were intended to improve the parameterisation of the Erosion 2D/3D model (Schmidt et al., 1996). The plots were larger $\left(44 \mathrm{~m}^{2}\right)$ than in all other experiments with slopes between $6 \%$ and $18 \%$. With few exceptions sequences of two simulations with dry spells $<12 \mathrm{~h}$ were carried out, while rainfall durations varied (Table 2). They lasted up to $100 \mathrm{~min}$ in the dry und $70 \mathrm{~min}$ in the very wet runs. Rainfall was applied using the equipment from the WB test site (Schramm, 1994), while combining more of the rainfall simulator units than used at $W B$ (Fig. 2). Rainfall intensities were comparably low (31-59 $\left.\mathrm{mm} \mathrm{h}^{-1}\right)$.

\subsection{Data compilation}

To combine all five data sets into one data base, which can be used for further runoff and infiltration studies, we followed a three-step approach: In a first step the methods to determine the different variable attributes were described and gaps in the data were indicated; in a second step the existing measurements were harmonized to international standards and in a third step data gaps were filled if possible; thus we distinguish between measured data, harmonized data and gap-filling data. Some rainfall simulations had to be deleted because of obvious errors or other inconsistencies in the data, which were often already indicated by the experimenter.

\subsubsection{Measured data}

2.3.1.1. Rain. The $F S, S Y$ and $F B$ data sets nearly always contain a sequence of a dry and a very wet run, while the WB data set comprises dry runs only. The WS data set contains all kind of possible combinations and encompasses sequences that consist of a dry run only and sequences that comprise combinations of a dry and/or wet and/or very wet run. For all 726 experiments the kinetic energy per unit of rain is known from the Veejet 80100 and 8070 nozzle characteristics and the given total rain amount of rain. Intensity is given as the ratio between rain amount and duration although a constant intensity was not verified during the experiments and some experimental notes even contained hints that intensity might not have been constant during the whole rain period.

2.3.1.2. Plot characteristics. All 209 plots were bordered by sheet steels driven into the topsoil or by a permanent wooden frame in the case of WS. Plot dimensions and slope gradient were measured in all cases.

2.3.1.3. Runoff characteristics. Time to runoff was recorded during most runs (644 of 726). Discharge was measured by collecting runoff with calibrated buckets at the lower end of the plots equipped with flow collection gutters. From rain intensity and measured runoff a first estimate of the infiltration rates can be derived from the difference between both. However, this ignores the initial ponding storage, which typically ranges from 0 to $4 \mathrm{~mm}$ of rainfall (e.g. Huang and Bradford, 1990; Mwendera and Feyen, 1992; Onstad, 1984). A more reasonable infiltration rate is given at the time to ponding $t_{P}$, when free water gets visible on the soil surface. It then equals rainfall intensity. From the difference between time to ponding and time to runoff $t_{R}$, when first runoff occurs at the plot outlet, ponding storage can be calculated and then used to correct the infiltrations rates at later stages (Horton, 1942). In the experimental protocols of $F S, S Y$ and WB time to ponding was defined as the time, when the soils started to remain glossy between two successive nozzle sprays. It was only measured in 284 out of 726 runs. The afterflow after the end of the rain was always discarded because it was not clear in all cases whether it had been measured properly because especially on very short plots a high frequency of measurement would have been necessary to capture the fast decay in runoff rate. 


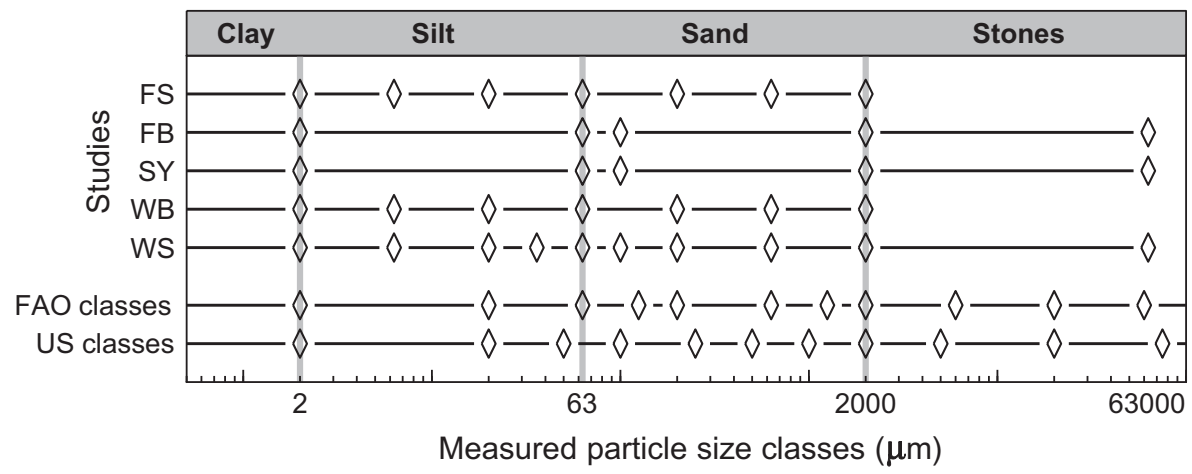

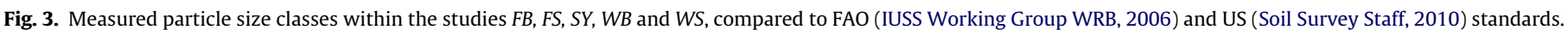

2.3.1.4. Soil. Soil moisture at the start of rain is regarded important for infiltration, slaking, runoff and erosion processes (Auerswald et al., 1994; Luk, 1985). Soil moisture was partly measured gravimetrically in a measuring depth of $0-0.03 \mathrm{~m}$ (97 out of 726; only in data sets FS and SY) and $0-0.3 \mathrm{~m}$ (107 out of 726; only data sets $F B$ and $W B$ ), respectively. A large but inconsistent number of other soil properties had been determined. For all 209 plots organic carbon content and total clay $(0.004-2 \mu \mathrm{m})$, silt $(2-63 \mu \mathrm{m})$ and sand $(63-2000 \mu \mathrm{m})$ contents in the fine earth fraction were available for the plough layer. For 86 out of 209 plots also stone content $(2-200 \mathrm{~mm})$ was recorded. Textural limits of sub-classes differed between the data sets as shown in Fig. 3. These differences and especially the lack of stone data in some data sets made harmonization necessary to yield soil texture of the bulk soil (see below). Soil pH was available in 136 and air-dry bulk density in 60 out of 209 cases.

2.3.1.5. Land use. Soil cover is regarded the most important influence on soil erosion. Total cover at the start of a rain sequence was given in 353 out of 370 cases, while data availability declined for vegetation cover, stone cover and residue cover with $88 \%, 77 \%$, and $68 \%$ of all 370 sequences, respectively.

Beside the cover information the data sets comprised information regarding the land management (tillage operations, fertilization, etc.), which, due to the multitude of management options, were inconsistent and just descriptive. To have a numerical variable in addition to cover, which should have an important influence on runoff generation, time since tillage TsT was added. It was available for 158 of all 370 rain sequences but could be estimated for the remaining ones based on the given descriptions of prior plot management. Its intention is to represent (to a certain degree) the tillage induced opening and weakening of the soil surface and the subsequent reconsolidation process. The opening and weakening is associated with a rapid increase in porosity (only partly measured in the data sets), a change in soil water and air regimes and a reduction of aggregate stability. In reverse, reconsolidation reduces the pore space, stabilizes aggregates and reestablishes hydraulically connected macro-pores (e.g. Ahuja et al., 2006; Fiener et al., 2011).

\subsubsection{Harmonized and gap-filled data}

2.3.2.1. Runoff. Accumulated runoff was recorded in variable time intervals. In some cases very short time intervals were used during the entire experiment, which caused strongly fluctuating runoff rates and which let to different weights of individual runs in the total data set. To facilitate data analysis we harmonized the data to have about 40-60 s intervals for all 726 runs. During this step we also added zero runoff data in 1-min intervals before the start of runoff. These data are usually neglected although they are valid measurements. The last time of zero runoff corresponds with the time to runoff $t_{R}$.

Time to runoff was recorded during 644 of all 726 runs. The $t_{R}$ gaps in the $F B$ and partly in the $W B$ data set were filled and tested for consistency with the measured $t_{R}$ values as follows: Firstly, a new variable 'time to plot response' $\left(t_{S}\right)$ was defined, while plotting a straight line through the first two measurements after $t_{R}$ and calculating the $X$-axis intersections of this line. Time to plot response is typically slightly larger than $t_{R}$. This results from the rapidly increasing runoff rates starting with zero at $t_{R}$. However, $t_{S}$ can be used to calculate $t_{R}$ from a regression between both variables. For development and validation, a split-sampling approach was applied. Every second data set of the ranked $t_{R}$ data was used to determine the regression based on logarithms of both variables due to the non-normality of $t_{R}$ and $t_{s}$. The other half was used for validation.

Time to ponding $t_{P}$ was only recorded during 284 of all 726 runs. In $F B$ and $W B$ no data are available, while sometimes this information was given for the WS data set. Moreover, $t_{P}$ is a somewhat more subjective measurement, as the definition of a glossy soil between two successive nozzle sprays allows for some wiggle room of individual researchers. Nevertheless, $t_{P}$ is important to estimate initial detention storage. Time to ponding was estimated using a regression analysis between $t_{P}$ and $t_{R}$, which again applied the split-sampling approach.

2.3.2.2. Soil. Soil descriptions were especially inconsistent and impeded the aggregation and analysis of different data sets. In the compiled studies total clay, silt and sand fractions were measured at 2,63 and $2000 \mu \mathrm{m}$, but additional information differed considerably regarding the number of sub-classes and especially in the measurement of stones (Fig. 3). None of the measurements matched exactly the standards by the FAO (IUSS Working Group WRB, 2006) or other widely used national standards, e.g. the US Soil Taxonomy (Soil Survey Staff, 2010) (Fig. 3). The geometric mean diameter $d_{g}$ and its standard deviation $S_{g}$ following Sinowski and Auerswald (1999) was calculated from all fine earth and stone fractions as integral texture variable to overcome these inconsistencies. It can be calculated and yields similar values independent from the particle size classes chosen for analysis. However, as the stone fraction was not given for all 209 plots ( $41 \%$ of all), it was necessary to estimate stone content from stone cover, while assuming that stone cover equals (volumetric) stone concentration of the topsoil. A bulk density for the stones equal to $2.65 \mathrm{~kg} \mathrm{~L}^{-1}$ and the bulk density of the soil, either measured or assumed to be $1.3 \mathrm{~kg} \mathrm{~L}^{-1}$, was used to convert the stone concentration $\left(\mathrm{L} \mathrm{L}^{-1}\right)$ into stone content $\left(\mathrm{kg} \mathrm{kg}^{-1}\right)$. Then the fine earth fractions could be recalculated as fraction of the bulk soil and finally $d_{\mathrm{g}}$ was derived. From the calculation of $d_{g}$ follows that the best interpolation of a 
certain unmeasured class of diameter $d$ like $<50 \mu \mathrm{m}$ as needed in the US texture system is given by:

$P_{<x}=P_{x-1}+\frac{P_{x+1}-P_{x-1}}{\lg \left(d_{x+1}\right)-\lg \left(d_{x-1}\right)} \cdot\left(\lg \left(d_{x}\right)-\lg \left(d_{x-1}\right)\right)$

where $P_{<x}$ denotes the unmeasured mass percentage below a certain grain diameter $d_{x}$, and the indices $x-1$ and $x+1$ refer to the properties for the next lower and higher measured class.

2.3.2.3. Land use. Gaps in TsT (78\% of all 726 runs) were filled based on crop stage information and the experience that a certain rather constant time after sowing is needed to reach a specific crop stage. Seedbed preparation and sowing then correspond with the last tillage except for no-till treatments. These estimates of TsT were based on local experiences and data given by Schwertmann et al. (1987).

Cover by a certain material like residues can be expressed in different ways like fraction of the total soil surface or fraction of the soil, which is not covered by other materials. To facilitate data analysis the data were converted as follows: Cover by vegetation $\left(\operatorname{Cov}_{\text {veg }}\right)$ is always given as fraction of the total soil surface; the cover by residues ( $C_{0} v_{\text {res }}$ ) is also given as fraction of the total soil surface but includes only that residue cover that is not covered by vegetation. Hence total cover by vegetation and residues can easily be calculated by adding both covers, but total residue cover including also those residues, which are shaded from the rain by vegetation, needs a recalculation $\left(\operatorname{Cov}_{\text {res,tot }}=\operatorname{Cov}_{\text {res }} /\left(1-\operatorname{Cov}_{\text {veg }}\right)\right.$ ). Analogously $\operatorname{Cov}_{\text {stone }}$ is given as fraction of the total soil surface but includes only stone cover that is not covered by vegetation or residues. Consequently total cover $\operatorname{Cov}_{\text {tot }}$ was calculated as sum of $C_{0 v} v_{v e g}$ Cov res, and Cov stone. Moreover, Cov res,tot and Cov stone,tot are also given in the compiled data base as these variables might be important in case of studying i.e. hydraulic roughness.

\subsection{Evaluation of data quality}

The range and distribution of data were evaluated by calculating kernel density distributions (Silverman, 1986). Within the groups of land use properties, plot properties, rain properties and soil properties many variables may be regarded independent variables in respect to runoff properties. To test this and to provide a measure of collinearity we calculated the coefficient of determination between the variables in each group, assuming linear relationships for sake of simplicity.

The measured rainfall/runoff data are subject to random measuring errors and to bias. Runoff rates can only be measured once at a certain point of time and hence random error cannot be quantified by repeated measurement but from the autocorrelation function as quantified in geostatistics. To this end experimental semivariograms were calculated using all 726 runs and a Gaussian model was fitted to the experimental data. Based on the theoretical semivariogram the nugget effect for all 726 runs could be determined, which is an indication for the random error.

To evaluate the quality of data harmonization and gap-filling in case of the estimates of time to runoff $t_{R}$ and time to ponding $t_{P}$ we validated our estimates using the second half of the data set not used for model development. In most other cases of harmonized and gap-filled data we extensively discuss potential error sources, even if a quantification of these errors is often hardly possible.

The statistical evaluations, e.g. kernel densities, were carried out with the statistical software tool GNU R (R Development Core Team, 2007) and the add-on package gstat (Bivand et al., 2008) in the case of geostatistics.

\section{Results and discussion}

\subsection{Data range}

A meta-data set offers three major advantages compared to individual data sets as created within certain research projects:

(i) The number of measurements is large. In total we have compiled 24,384 runoff measurements for which most other data are available as well. The number of flagged (missing but gap filled) auxiliary rain, plot land use and soil parameters varies between $0 \%$ and $100 \%$ (Table 3 ). Rainfall, runoff and plot data are always available. The lowest availability is given for some soil data, especially soil moisture in different depth and time since tillage $(<30 \%)$.

(ii) A meta-data set allows to examine the validity of a relation under a wide set of conditions (Figs. 4-7) while the individual data sources had only a limited range of a certain parameters due to scientific and technical reasons. The scientific rationale to examine a certain influence leaving other influences constant necessarily restricts even the validity of the varied influence within a narrow range given by the other, constant influences. While these restrictions level out in a meta-data base, those which are caused by the attempt to allow comparison to other researches still appear. Hence rain intensity peaks around $65 \mathrm{~mm} \mathrm{~h}^{-1}$ (Fig. 5) to allow comparison with any results obtained with the rainulator (Meyer and McCune, 1958) and the Swanson simulator (Swanson, 1965) although intensity was constructively fixed only in one data source (WS). Slope gradient peaks at $9 \%$ (Fig. 4) due to the standard defined by Wischmeier et al. (1958). Even more important are the technical restrictions, which are especially due to the rainfall simulator and the landscape. The rainfall simulator determines the rain properties but also the plot dimensions (Fig. 2), which hence varied only within a very narrow range within each data source (Fig. 4). The landscape limits the range of soil and land use properties. These strong limitations within individual data sources are true for most of the parameters compiled here. As an example it is illustrated for the temporal distribution, which shows that due to the concentration within measuring campaigns, the individual data sources only covered narrow ranges within individual years, while a coverage of the year almost corresponding to the distribution of rain erosivity resulted from the combination of the different sources (Fig. 5). The range of influences covered by the meta-data set is quantified in Table 3 and the distribution within this range is illustrated for major plot (Fig. 4), rain (Fig. 5), soil (Fig. 6), and land use conditions (Fig. 7). They illustrate the large range for all influencing parameters like soil, rain, plot or land use properties, which cover at least one order of magnitude with very few exceptions like plot width (1-2 m), bulk density (1070$1750 \mathrm{~kg} \mathrm{~m}^{-3}$ ) and the specific kinetic energy of rain (only 12 and $20 \mathrm{~J} \mathrm{~m}^{-2} \mathrm{~mm}^{-1}$ ). The large range of influencing factors causes a correspondingly large range in the runoff response (Fig. 8); e.g., time to runoff varied by more than two orders of magnitude and the runoff coefficient covered almost the full possible range from 0 to 1 . It has to be noted that the advantageous range and distribution shown may be lost if the total data set is broken down to specific conditions. E.g., limiting the data evaluation to seedbed conditions after long-term bare follow will leave only the data source WS and its specific restrictions. However, a less restrictive break down to bare seed bed conditions will also leave all data from source $S Y$ and several other data from the other sources. 
Table 3

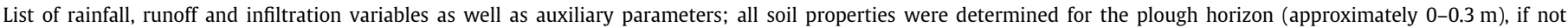

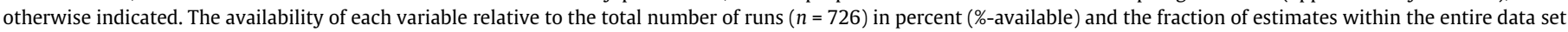
(\%-flagged) are given.

\begin{tabular}{|c|c|c|c|c|c|}
\hline Variable (abbreviation) & Description & Unit & Range & $\%$-available & \%-flagged \\
\hline$p$ & Rain intensity & $\mathrm{mm} \mathrm{h}^{-1}$ & 29-99 & 100 & 0 \\
\hline$P_{\text {tot }}$ & Total rainfall applied during simulation & $\mathrm{mm}$ & $11-99$ & 100 & 0 \\
\hline$q$ & Runoff intensity & $1 s^{-1}$ & $0-0.5$ & 100 & 0 \\
\hline$Q$ & Total runoff without afterflow & $\mathrm{mm}$ & $0-59$ & 100 & 0 \\
\hline$t_{P}$ & Time to ponding & $\mathrm{s}$ & $4-1047$ & 100 & 61 \\
\hline$t_{R}$ & Time to runoff & $\mathrm{s}$ & $6-3588$ & 100 & 11 \\
\hline Length & Length of the simulation plot & $\mathrm{m}$ & $4-22$ & 100 & 0 \\
\hline Width & Width of the simulation plot & $\mathrm{m}$ & $1-2$ & 100 & 0 \\
\hline Slope & Slope of the simulation plot & $\%$ & $1.6-23.6$ & 100 & 0 \\
\hline $\mathrm{Cl}_{\text {tot }}$ & Total clay content $(0.004-2 \mu \mathrm{m})$ in $\mathrm{BS}^{\mathrm{a}}(\mathrm{w} / \mathrm{w})$ & $\%$ & $2-61$ & 100 & 0 \\
\hline$S i_{\text {tot }}$ & Total silt content $(2-63 \mu \mathrm{m})$ in $\mathrm{BS}(\mathrm{w} / \mathrm{w})$ & $\%$ & $6-86$ & 100 & 0 \\
\hline$S a_{\text {tot }}$ & Total sand content $(63-2000 \mu \mathrm{m})$ in BS $(w / w)$ & $\%$ & $2-87$ & 100 & 0 \\
\hline$C_{\text {org }}$ & Soil organic carbon content in $\mathrm{FEF}^{\mathrm{b}}$ & $\%$ & $0.5-3.5$ & 100 & 0 \\
\hline $\mathrm{pH}$ & $\mathrm{pH}$ & - & $4.5-7.5$ & 85 & 0 \\
\hline Skeleton & Total sum of stones $(2-200 \mathrm{~mm})$ in BS $(w / w)$ & $\%$ & $0-63$ & 100 & 27 \\
\hline$B D$ & Air-dry bulk density & $\mathrm{kg} \mathrm{m}^{-3}$ & $1070-1750$ & 38 & 60 \\
\hline$d_{g}$ & Geometric mean particle diameter & $\mu \mathrm{m}$ & $1-737$ & 100 & 0 \\
\hline vfSi & Very fine silt $(2-6.3 \mu \mathrm{m})$ in $\mathrm{BS}(\mathrm{w} / \mathrm{w})$ & $\%$ & $0-27$ & 100 & 27 \\
\hline$f S i$ & Fine silt $(6.3-20 \mu \mathrm{m})$ in $\mathrm{BS}(\mathrm{w} / \mathrm{w})$ & $\%$ & $1-33$ & 100 & 27 \\
\hline$m S i$ & Medium silt $(20-36 \mu \mathrm{m})$ in $\mathrm{BS}(\mathrm{w} / \mathrm{w})$ & $\%$ & $1-31$ & 100 & 27 \\
\hline$c S i$ & Coarse silt $(36-63 \mu \mathrm{m})$ in $\mathrm{BS}(\mathrm{w} / \mathrm{w})$ & $\%$ & $1-35$ & 100 & 27 \\
\hline$v f S a$ & Very fine sand $(63-100 \mu \mathrm{m})$ in $\mathrm{BS}(\mathrm{w} / \mathrm{w})$ & $\%$ & $0-19$ & 100 & 12 \\
\hline$f S a$ & Fine sand $(100-200 \mu \mathrm{m})$ in $\mathrm{BS}(\mathrm{w} / \mathrm{w})$ & $\%$ & $0-49$ & 100 & 27 \\
\hline$m S a$ & Medium sand $(200-630 \mu \mathrm{m})$ in $\mathrm{BS}(\mathrm{w} / \mathrm{w})$ & $\%$ & $0.4-61$ & 100 & 27 \\
\hline$c S a$ & Coarse sand $(630-2000 \mu \mathrm{m})$ in $\mathrm{BS}(\mathrm{w} / \mathrm{w})$ & $\%$ & $0-35$ & 100 & 27 \\
\hline$v f S t$ & Very fine stones $(2-6.3 \mathrm{~mm})$ in BS $(\mathrm{w} / \mathrm{w})$ & $\%$ & $0-31$ & 100 & 100 \\
\hline fSt & Fine stones $(6.3-20 \mathrm{~mm})$ in $\mathrm{BS}(\mathrm{w} / \mathrm{w})$ & $\%$ & $0-16$ & 100 & 100 \\
\hline$m S t$ & Medium stones $(20-63 \mathrm{~mm})$ in $\mathrm{BS}(\mathrm{w} / \mathrm{w})$ & $\%$ & $0-16$ & 100 & 100 \\
\hline$c S t$ & Coarse stones $(63-200 \mathrm{~mm})$ in $\mathrm{BS}(\mathrm{w} / \mathrm{w})$ & $\%$ & - & 100 & 100 \\
\hline$\theta_{\text {surf }}$ & Volumetric antecedent surface soil moisture $(0-3 \mathrm{~cm}$ depth) & $\%$ & $2-26$ & $13 /(29)^{c}$ & 0 \\
\hline$\theta_{\text {plough }}$ & Volumetric antecedent soil moisture in the plough layer $(0-30 \mathrm{~cm}$ depth $)$ & $\%$ & $8-44$ & $15 /(21)$ & 0 \\
\hline Cov $_{\text {tot }}$ & Total surface cover (sum of cover by stones, plants and residues) & $\%$ & $0-93$ & 100 & 4 \\
\hline Cover & Cover by vegetation & $\%$ & $0-90$ & 89 & $>1$ \\
\hline Cov & Cover by residues & $\%$ & $0-18$ & 89 & 18 \\
\hline Cov stone $^{2}$ & Cover by stones & $\%$ & $0-35$ & 89 & 7 \\
\hline TsT & Time since tillage & $\mathrm{d}$ & $0.04-227$ & 100 & 63 \\
\hline
\end{tabular}

a Bulk soil.

b Fine earth fraction.

c The number in brackets represents percentage of the dry runs.

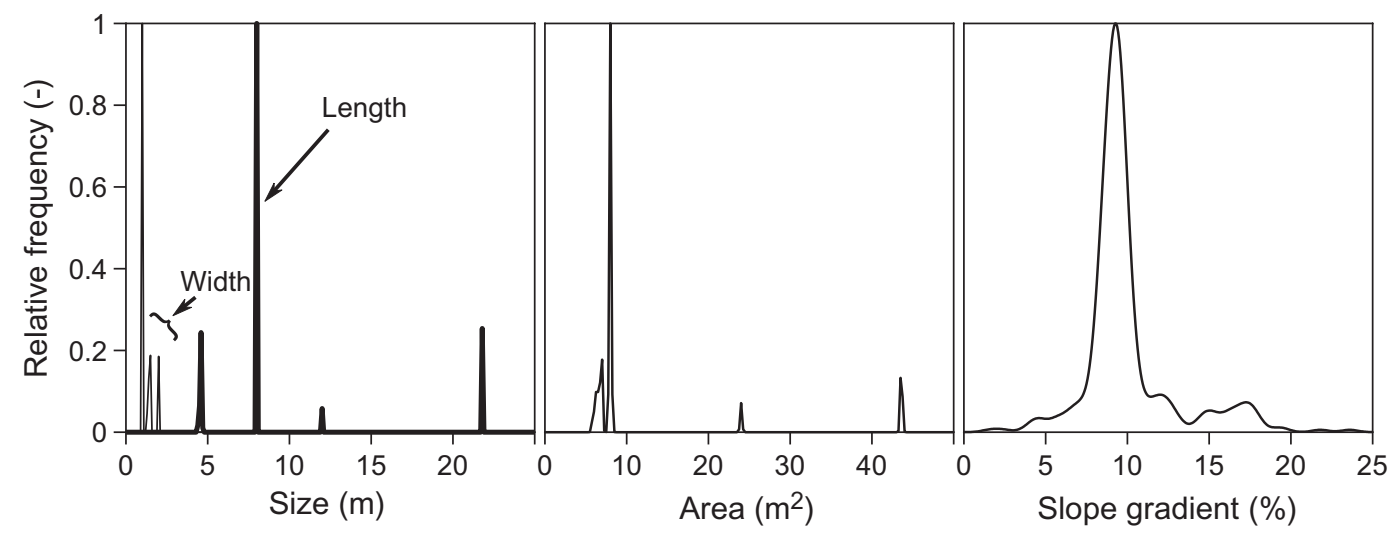

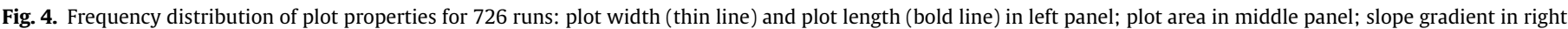
panel. Maximum frequency was set to 1 .

(iii) Soil, land use, plot or rain properties often closely correlate within individual sources and cause a collinearity of influencing factors. For example, kinetic rain energy applied to the soil surfaces often only is varied by varying either soil cover or rain intensity, or rain duration or the specific energy per rain depth. Hence, within an individual source, which may vary kinetic energy by changing rain intensity, it becomes impossible to isolate the influence of kinetic energy from the influence of the higher water supply to the soil surface, while all reasons for a variation of kinetic energy are varied in the meta-data set and thus allow to quantify the influence kinetic energy itself. The precondition for analyzing an individual influence hence is that collinearity is small. Breaking the collinearity is especially difficult among soil 

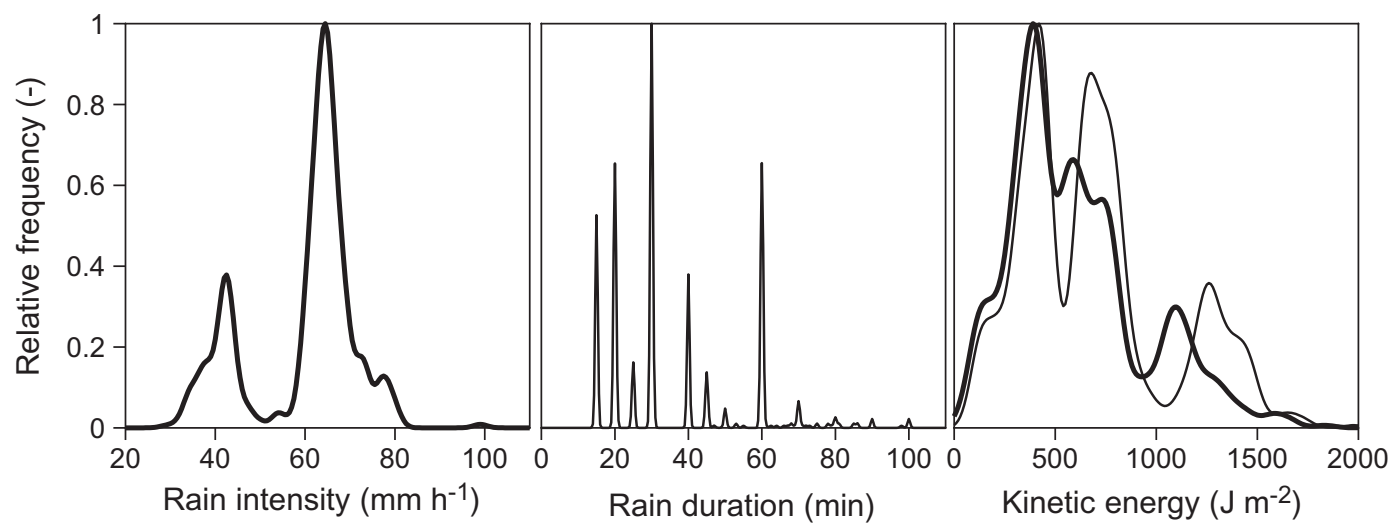

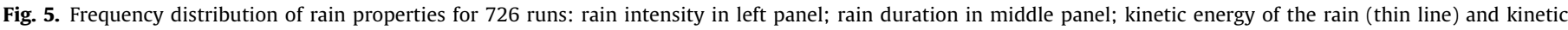
energy proportionally reduced according to total soil cover (bold line) in right panel. Maximum frequency was set to 1 .

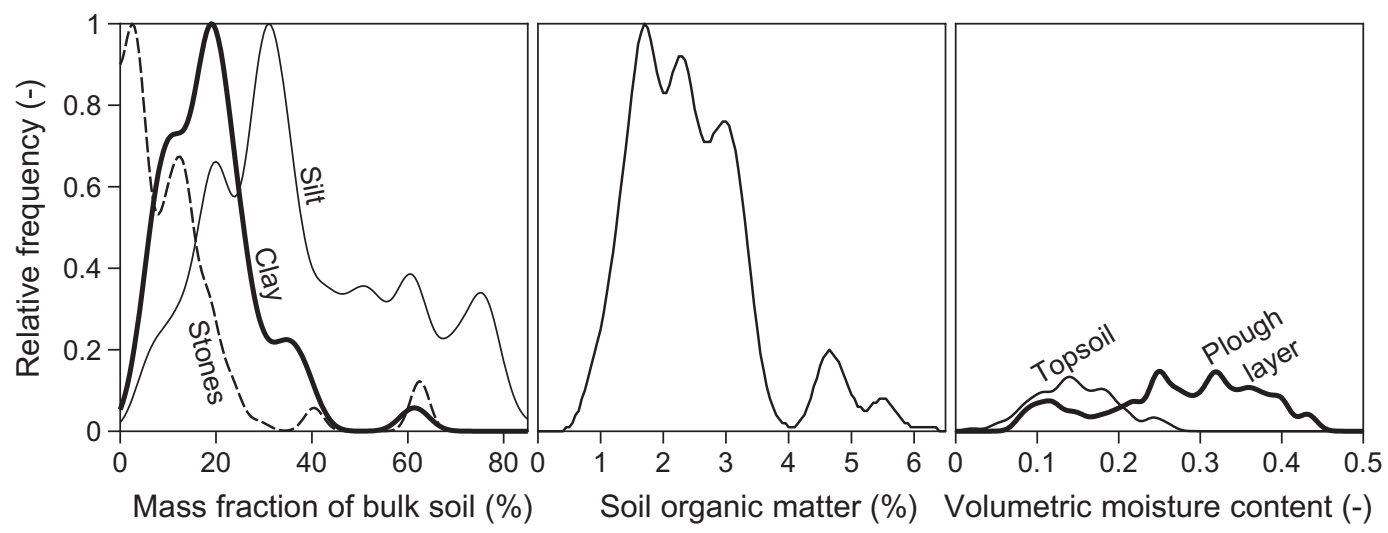

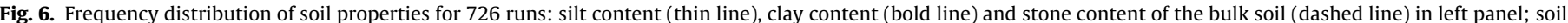

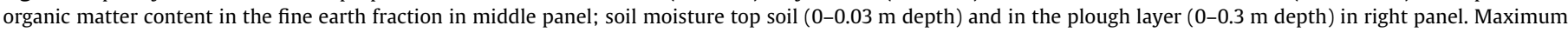
frequency for the full data set of 726 runs was set to 1 and proportionally lower where data availability was lower (soil moisture contents).

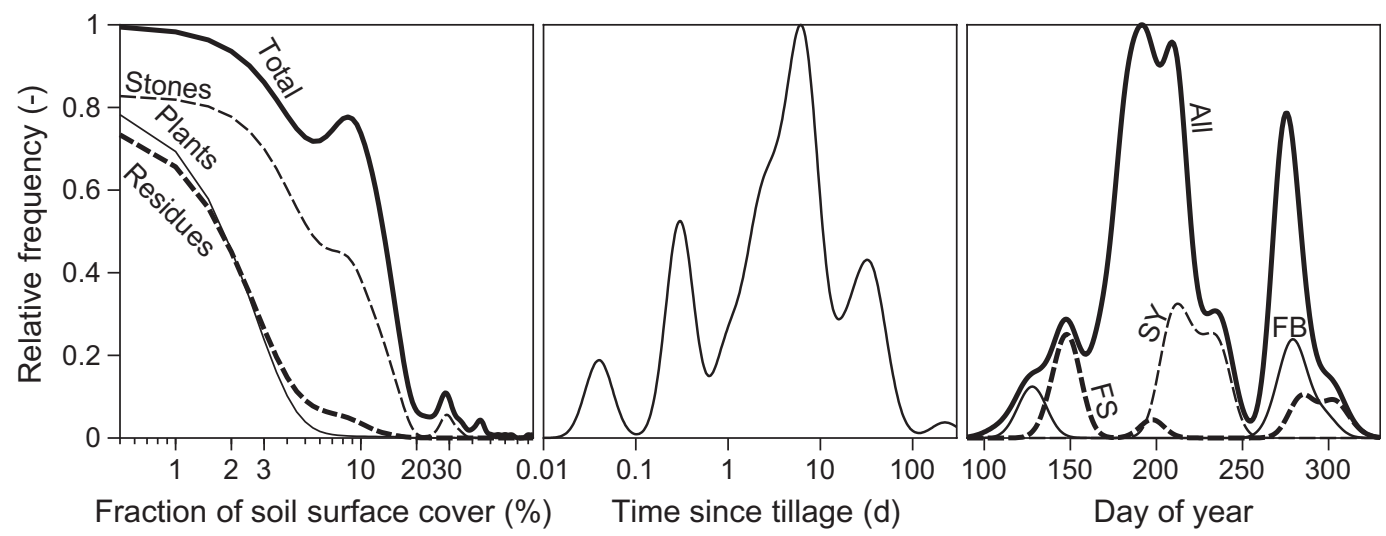

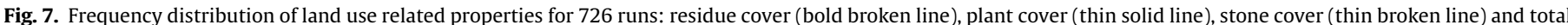

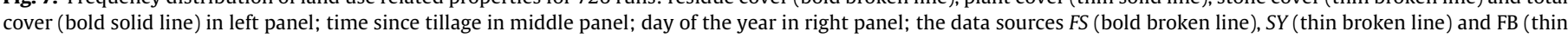

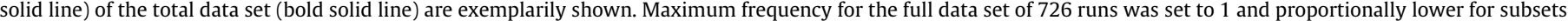
(day of year) or incomplete data (cover).

properties, because within an individual landscape usually many soil properties change in close correlation. Within the meta-data set the collinearity within rain properties, soil properties and within land use properties became sufficiently small. The coefficient of determination $\left(R^{2}\right)$ among the individual parameters usually remained well below $50 \%$ (Table 4). Parameters, which still correlate rather closely are rain amount vs. rain duration $\left(R^{2}=75 \%\right)$ and silt content vs. sand content $\left(R^{2}=57 \%\right)$. A rather high collinearity, however, can also be found among plot dimensions. When plots became longer they also became wider $\left(R^{2}=51 \%\right)$ and an even stronger correlations exists to plot area as it is calculated from length and width $\left(R^{2}=98 \%\right)$. Although the significance of these coefficients of determination is rather small 


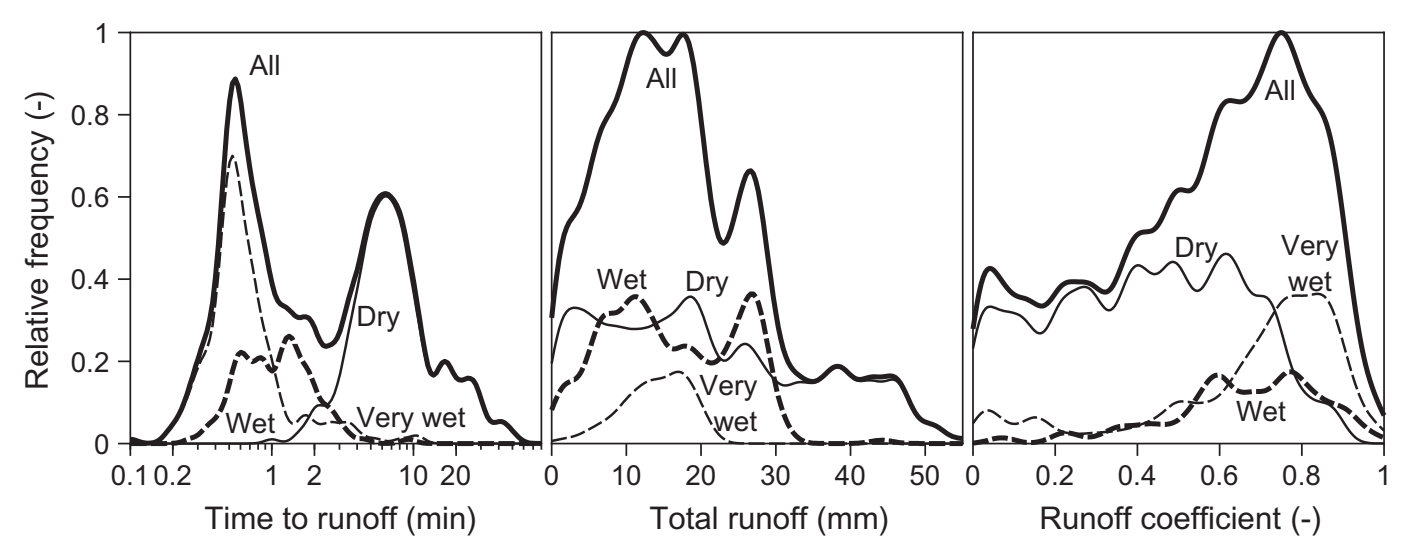

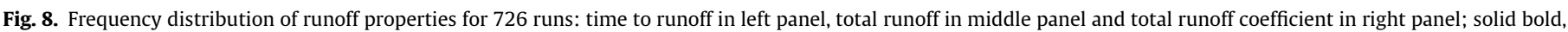

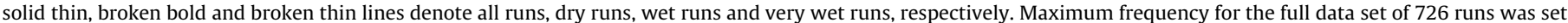
to 1 and proportionally lower for incomplete data (time to runoff) or subsets (dry, wet, and very wet runs).

Table 4

Coefficients of determination between independent variables in the total data set. Variables are grouped in land use properties, plot properties, rain properties and soil properties. Coefficients larger than $50 \%$ are given in bold type. Cover is given as vegetation $\mathrm{Cov}_{v e g}$ and total cover $\mathrm{Cov}_{\text {tot }}$; rainfall properties are indicated by specific kinetic rainfall energy $e P$, intensity, total rainfall $P_{t o t}$ and rain duration; soil properties comprise total clay $\mathrm{Cl}_{\text {tot }}$, silt $\mathrm{Si}_{\text {tot }}$ and sand $\mathrm{Sa}_{\text {tot }}$ content, skeleton content as well as soil organic carbon $S O C$ and $\mathrm{pH}$ value.

\begin{tabular}{|c|c|c|c|c|c|c|}
\hline Land use properties & Cov veg $_{\text {veg }}$ & $\mathrm{Cov}_{\text {tot }}$ & TsT & & & \\
\hline $\operatorname{Cov}_{\text {veg }}$ & 1 & 0.47 & 0.17 & & & \\
\hline Cov tot & & 1 & 0.40 & & & \\
\hline TsT & & & 1 & & & \\
\hline Plot properties & Area & Width & Length & Slope & & \\
\hline Area & 1 & 0.65 & 0.98 & 0.04 & & \\
\hline Width & & 1 & 0.51 & 0.13 & & \\
\hline Length & & & 1 & 0.03 & & \\
\hline Slope & & & & 1 & & \\
\hline Rain Properties & $e P$ & Intensity & $P_{\text {tot }}$ & Duration & & \\
\hline$e P$ & 1 & 0.28 & 0.11 & 0.03 & & \\
\hline Intensity & & 1 & 0.04 & 0.08 & & \\
\hline & & & 1 & 0.75 & & \\
\hline Duration & & & & 1 & & \\
\hline Soil properties & $\mathrm{Cl}_{\text {tot }}$ & $S i_{\text {tot }}$ & $S a_{\text {tot }}$ & Skeleton & SOC & $\mathrm{pH}$ \\
\hline$C l_{\text {tot }}$ & 1 & 0.07 & 0.10 & 0.18 & 0.04 & 0.39 \\
\hline$S i_{\text {tot }}$ & & 1 & 0.53 & 0.36 & 0.14 & 0.10 \\
\hline$S a_{\text {tot }}$ & & & 1 & 0.00 & 0.01 & 0.00 \\
\hline Skeleton & & & & 1 & 0.47 & 0.20 \\
\hline $\mathrm{SOC}$ & & & & & 1 & 0.17 \\
\hline $\mathrm{pH}$ & & & & & & 1 \\
\hline
\end{tabular}

due to spurious relations they illustrate that it is impossible to analyze the influence of plot length independent from plot width. To break this correlation a data set would be necessary, in which the plots are wider than long but to our knowledge such an experiment has never been conducted. However, in reality no correlation between width and length of fields exist because fields can be oriented perpendicular to or in direction of slope. Hence, the rainfall experiments represent only situations of fields being oriented in slope direction although in some cases tillage direction perpendicular to slope has been evaluated. Notably this is a rather rare case that a field oriented in slope direction is farmed perpendicular to slope. However, the plot dimensions (Fig. 4) show the most unfavorable distribution and the strongest collinearity (Table 4), and hence appear to be statistically the most unfavorable property in rainfall simulations studies. Nevertheless, it is interesting to note that the standardisation of plot dimensions, especially by Wischmeier and Smith while developing the Universal Soil Loss Equation (Wischmeier and Smith, 1960), was and is the basis for sound statistical analyses of soil erosion and surface runoff under different site-conditions.

\subsection{Data quality}

Data quality is given by data availability and data accuracy. Data availability was improved by homogenization and gap filling, which may have decreased accuracy. Hence we try to quantify accuracy of the data.

\subsubsection{Runoff}

Time to runoff and time to ponding were missing for 82 and 442 out of 726 runs. They could be estimated with the following regressions:

$\log \left(t_{R}\right)=1.131 \cdot \log \left(t_{s}\right)-0.462 \quad\left(R^{2}=0.97 ; p<0.001 ; n=322\right)$

$\log \left(t_{P}\right)=0.880 \cdot \log \left(t_{R}\right)-0.118 \quad\left(R^{2}=0.81 ; p<0.001 ; n=142\right)$

Validation with that half of measurements that were not used for establishing these equations yielded a sufficient $R^{2}$ and root mean squared error (Fig. 9). In case of $t_{P}$ the slope of the regressions deviated somewhat from 1 and indicated that especially very short $t_{P}$ may be overestimated by a few seconds.

For the most important data, the measurements of runoff rates, geostatistical analysis predicted a nugget effect, which corresponded to a standard deviation of $0.009 \mathrm{~L} \mathrm{~s}^{-1}$ while mean and maximum runoff rates were $0.107 \mathrm{~L} \mathrm{~s}^{-1}$ and $0.459 \mathrm{~L} \mathrm{~s}^{-1}$ respectively. Hence, for an individual measurement of runoff rate a $95 \%$ interval of confidence of $\pm 0.02 \mathrm{~L} \mathrm{~s}^{-1}$ must be expected, that decreases with increasing number of measurements. In many cases final runoff rate within a sequence became near constant. Ten near constant runoff rates would then allow quantifying final runoff rate with $\pm 0.007 \mathrm{~L} \mathrm{~s}^{-1}$. The error results from errors in the runoff measurement itself and short-term within-rain variation in rainfall intensity, e.g. due wind effects or due to the intermittent pass of the spay cone. However, it is worth mentioning that the nugget effect not only results from measuring errors but could also result from a natural variability of surface runoff, e.g. due to sudden release of water dammed behind residues or soil clods. 


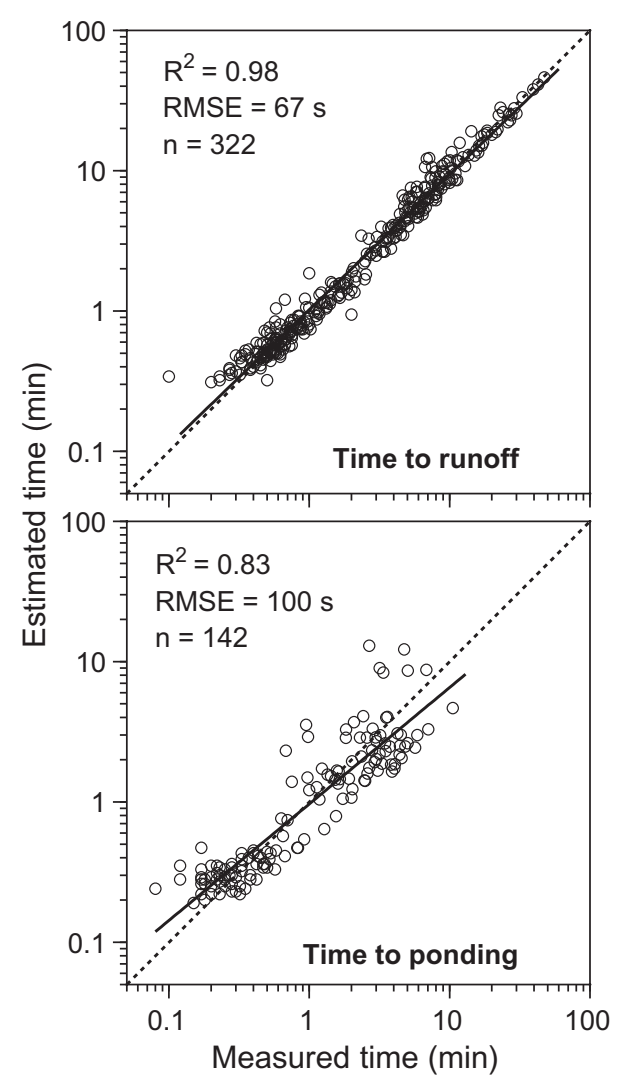

Fig. 9. Validation of the estimated vs. measured time to runoff $t_{R}$ and time to ponding $t_{P}$, respectively with half of the data set that was not used for the development of the prediction equations; coefficient of determination $\left(R^{2}\right)$ and Root Mean Square Errors (RMSEs) are given in both figures.

Additional bias in runoff measurements can result from incorrect and inhomogeneous rainfall depth and intensity measurements (varying water pressure, partly logged nozzles), from errors in determining plot size and rainfall area due to boundary effects at the steel sheets, and/or from runoff measurements itself. Quantification of bias of individual rainfall simulations is not possible but should become small especially when several data sources are combined as done here.

\subsubsection{Rain}

Data on accuracy of rain properties is usually not given. Rain duration should have a marginal error. Specific kinetic energy of the rain can only be taken from literature if the proper water pressure was applied at the nozzle. Whether this was the case had only been measured during all runs and for all nozzles by one source (SY), while this information was lacking for the other sources. Also, independent or replicated measurements of rain amount or rain intensity were missing. It appears that two out of the three most important rainfall simulation data are only weakly founded. In cases where runoff and hence infiltration rate had become near constant in a previous rain it may be compared to the near-constant runoff rate in the following rain. Deviations may indicate errors in rain intensity. In most such cases both final infiltration rates agreed, but deviations of up to five in few cases even up to $10 \mathrm{~mm} \mathrm{~h}^{-1}$ to both sides appeared, which may also include systematic errors in measuring runoff rate. Runs with deviations $>5 \mathrm{~mm} \mathrm{~h}^{-1}$ were excluded during the compilation of the data base. Within-rain variations (in time and in space) also will happen, e.g. due to clogged nozzles or declining water pressure but were documented only for source SY. We may estimate that the error during a
$60 \mathrm{~mm}$ rainfall simulation for $1 \mathrm{~h}$ is typically in a range of $\pm 5 \mathrm{~mm}$. In some cases a maximum error of $\pm 10 \mathrm{~mm}$ can be expected.

\subsubsection{Evapotranspiration}

Calculating infiltration from rain intensity minus runoff rate is a simplification of the water balance as it ignores evapotranspiration losses. Assuming an evapotranspiration rate of $4 \mathrm{~mm} \mathrm{~d}^{-1}$ during a typical dry day used for a rainfall simulation experiment, leads to a maximum loss during a 1 -h rainfall simulation of $0.5 \mathrm{~mm}(4 \mathrm{~mm} /$ $8 \mathrm{~h}$ ). Hence, evapotranspiration losses can be widely neglected during the simulations but may become important in the case of sequences that cover one to 2 days. In those cases evaporation losses may be estimated from the meteorological data of the closest station (see NOAA NCDC Climate Data Online, 2011).

\subsubsection{Plot dimensions}

The true dimension of the plots can typically be measured with a precision of $\pm 0.02 \mathrm{~m}$, but under some conditions, e.g. dense (and tall) vegetation, only a precision of $\pm 0.05 \mathrm{~m}$ can be reached. Moreover, there might be uncontrollable inflows and outflow due to leaky borders, mouse holes, etc. However, the main problem are the sheet steel or wooden plot borders (approx. height above the surface: $0.10 \mathrm{~m}$ ) itself as these collect additional water in case of not fully vertical rainfall coming from the simulator nozzles (virtual increase in plot width and length of up to approx. 0.025-0.05 $\mathrm{m}$ on each side of a plot). In case of a $7 \mathrm{~m}^{2}$ plot (FS, SY and WS) and a rain intensity of $60 \mathrm{~mm} \mathrm{~h}^{-1}$ a typical and a maximum error in rainfall depth of approximately $0.6-1.8 \mathrm{~mm}$ can be expected due to erroneous plot dimensions, while the plot borders add approximately another $2.3-4.6 \mathrm{~mm}$. Assuming that these errors are not always uniform an overall typical overestimation of roughly $1.5-3 \mathrm{~mm}$, and a maximum overestimation of roughly 3-6 $\mathrm{mm}$ seem to be a reasonable estimate.

\subsubsection{Soil}

Regarding the accuracy of the soil data we have to refer to the original publications as no measure of accuracy can be derived from the meta-data set itself. The most important parameters, which were missing in many cases, were stone content and soil moisture. This is surprising because texture parameters but also the influence of other soil parameters like soil organic matter cannot be analyzed properly if stone content is missing. Our procedure to estimate stone content from stone cover should yielded in fairly good estimates if we consider that even in cases where stones were measured these measurements have larger error than other texture parameters because at large volume of soil needs to be sampled and sieved for an accurate determination of stone content on the scale of a plot. Also the lack of soil moisture data is surprising given that moisture is regarded an important influence for the infiltration, detachment and runoff processes. We found no possibility to estimate moisture from other properties. It even was not possible to estimate moisture at the soil surface $(0-0.3 \mathrm{~m})$ from moisture in the plough horizon $(0-0.3 \mathrm{~m})$ and vice versa. This is illustrated by the contrasting direction of correlations (not significant) of both soil moisture depths to runoff coefficients of the dry runs. The uppermost soil moisture $(0-0.03 \mathrm{~m})$ correlated negatively to the runoff coefficient while soil moisture of the plough layer $(0-0.3 \mathrm{~m})$ correlated positively, although in both cases correlation was weak $\left(R^{2}<0.10\right)$. This indicates that both moisture properties act more or less independently and in opposite ways, which would not be the case if both were closely and positively correlated.

\subsubsection{Land use}

Land use is only quantified in the meta-data sets by crop type, soil cover and TsT. Plant height which would also be important 
regarding the effect of cover was not recorded in the respective data sources but should correlate to plant cover for a specific crop. TsT had to be estimated especially in cases where it is high. Given the expectation that the effect of TsT decreases exponentially with increasing TsT we can still be confident in these estimates, because on a logarithmic scale the possible misjudgements are small due to the fact that crops develop in a rather narrow time window within a certain landscape. On the logarithmic scale the very short TsT must be regarded more inaccurate because the data sources in these cases only reported ranges ("a few hours before", "a few days before") that did not allow differentiation within this time scale except for the lowest value ("1 h before rain").

\section{Conclusions and recommendations}

In general the compiled data base of rainfall simulations (Seibert et al., 2011) widely broadens the scientific benefit of the individual data sets for two reasons: (i) Runoff and infiltration on arable land can be studied under a much wider spectrum of rainfall, soil and land management conditions. (ii) A large data base should at least partly overcome the problems of the uncertainties in individual measurements which may result from a multitude of potential systematic and random errors.

The most important gaps as identified in this meta-analysis were: (i) A limited range of examined situations, which could only partly be overcome by the meta-data set; this applies especially for the specific kinetic energy of the rain, for rain intensity, for plot dimensions and for the slope gradient. (ii) Lacking data on stones, time to ponding, mulch cover and also on soil moisture. (iii) Inconsistencies in measurements and reporting; this applied especially for soil texture and stone content. A side effect of this meta-data analysis may be that it may foster the definition of minimum requirements regarding measurements and data reporting in rainfall simulation studies.

The data base does not contain sediment concentrations although those were measured. However, there were inconsistencies between the data sources, which could not be solved. Hence we did not include the sediment data in the data set but a subset of sediment data, which seems to be reliable, can be obtained on request from the authors.

\section{Acknowledgements}

We gratefully acknowledge the work and efforts of all research groups colleting the data set used in this meta-analysis, especially K. Gerlinger, J. Haider, W. Martin and A. Michael. This research was conducted within the German Research Agency (DFG) project DI 639/1-1 (Markus Disse); the financial support by the DFG is acknowledged.

\section{References}

Adams, R., Parkin, G., Rutherford, J.C., Ibbitt, R.P., Elliott, A.H., 2005. Using a rainfall simulator and a physically based hydrological model to investigate runoff processes in a hillslope. Hydrol. Proc. 19, 2209-2223.

Ahuja, L.R., Ma, L., Timlin, D.J., 2006. Trans-disciplinary soil physics research critical to synthesis and modeling of agricultural systems. Soil Sci. Soc. Am. J. 70, 311326.

Arnaez, J., Lasanta, T., Ruiz-Flaño, P., Ortigosa, L., 2007. Factors affecting runoff and erosion under simulated rainfall in Mediterranean vineyards. Soil Tillage Res. 93, 324-334.

Assouline, S., Mualem, Y., 2006. Runoff from heterogeneous small bare catchments during soil surface sealing. Water Resour. Res. 42, W12405.

Auerswald, K., 1986. A Swanson-type rainfall simulator for erosion studies. Mitteilgn. Dtsch. Bodenkdl. Gesellsch. 49, 224-225.

Auerswald, K., Haider, J., 1996. Runoff curve numbers for small grain under German cropping conditions. J. Environ. Manage. 47, 223-228.

Auerswald, K., Mutchler, C.K., McGregor, K.C., 1994. The influence of tillage-induced differences in surface moisture content on soil erosion. Soil Tillage Res. 32, 4150.
Auerswald, K., Weigand, S., Kainz, M., Philipp, C., 1996. Influence of soil properties on the population and activity of geophagous earthworms after five years of bare fallow. Biol. Fertility Soils 23, 382-387.

Baker, J.L., Laflen, J.M., Johnson, H.P., 1978. Effect of tillage systems on runoff losses of pesticides, a rainfall simulation study. Trans. ASAE 21, 886-892.

Bivand, R.S., Pebesma, E.J., Gómez-Rubio, V., 2008. Applied Spatial Data Analysis with R. Springer, New York, USA.

Bryan, R.B., 1970. An improved rainfall simulator for use in erosion research. Can. J. Earth Sci. 7, 1552-1561.

Evrard, O., Vandaele, K., Bielders, C., Van Wesemael, B., 2008. Seasonal evolution of runoff generation on agricultural land in the Belgian loess belt and implications for muddy flood triggering. Earth Surf. Process. Landforms 33, 1285-1301.

Fiener, P., Auerswald, K., 2003. Concept and effects of a multi-purpose grassed waterway. Soil Use Manage. 19, 65-72.

Fiener, P., Auerswald, K., 2009. Spatial variability of rainfall on a sub-kilometre scale. Earth Surf. Proc. Land. 34, 848-859.

Fiener, P., Auerswald, K., Van Oost, K., 2011. Spatio-temporal patterns in land use and management affecting surface runoff response of agricultural catchments a review. Earth-Sci. Rev. 106, 92-104.

Gerlinger, K., 1997. Erosionsprozesse auf Lössböden: Experimente und Modellierung. PhD thesis, Universität Karlsruhe (TH), Karlsruhe, Germany.

Haider, J., 1994. Herbizide in Oberflächenabfluß und Bodenabtrag - Feldversuche mit simulierten Regen. PhD thesis, TU München, Freising-Weihenstephan, Germany.

Haygarth, P.M., Bilotta, G.S., Bol, R., Brazier, R.E., Butler, P.J., Freer, J., Gimbert, L.J., Granger, S.J., Krueger, T., Macleod, C.J.A., Naden, P., Old, G., Quinton, J.N., Smith, B., Worsfold, P., 2006. Processes affecting transfer of sediment and colloids, with associated phosphorus, from intensively farmed grasslands: an overview of key issues. Hydrol. Proc. 20, 4407-4413.

Horton, R.E., 1942. Simplified method of determining an infiltration-capacity curve from an infiltrometer-experiment. Trans. Am. Geophys. Union 23, 570-574.

Huang, C., Bradford, J.M., 1990. Depressional storage for Markov-Gaussian surfaces. Water Resour. Res. 26, 2235-2242.

Hurlbert, S.H., 1984. Pseudoreplication and the design of ecological field experiments. Ecol. Monogr. 54, 187-211

IUSS Working Group WRB, 2006. World Reference Base for Soil Resources 2006. World Soil Resources Reports 103, FAO, Rome, Italy, pp. 1-145.

Kainz, M., Auerswald, K., Vöhringer, R., 1992. Comparison of German and Swiss rainfall simulators - utility, labour demands and costs. Z. Pflanzenernähr. Bodenkd. 155, 7-11.

Lal, R., 2001. Soil degradation by erosion. Land Degrad. Dev. 12, 519-539.

Le Bissonnais, Y., Cerdan, O., Lecomte, V., Benkhadra, H., Souchère, V., Martin, P., 2005. Variability of soil surface characteristics influencing runoff and interrill erosion. Catena 62, 111-124.

Luk, S.H., 1985. Effect of antecedent soil moisture content on rainwash erosion. Catena 12, 129-139.

Martin, W., 1988. Die Erodierbarkeit von Böden unter simulierten und natürlichen Regen und ihre Abhängigkeit von Bodeneigenschaften. PhD thesis, TU München, Freising-Weihenstephan, Germany.

Meyer, L.D., 1960. Use of the rainulator for runoff plot research. Soil Sci. Soc. Am. Proc. 24, 319-322.

Meyer, L.D., McCune, D.L., 1958. Rainfall simulator for runoff plots. Agric. Eng. 19, 644-648.

Michael, A., 2001. Anwendung des physikalisch begründeten Erosionsprognosemodells EROSION 2D/3D. Empirische Ansätze zur Ableitung der Modellparameter. PhD thesis, Technische Universität Bergakademie, Freiberg, Germany.

Mwendera, E.J., Feyen, J., 1992. Estimation of depression storage and Manning's resistance coefficient from random roughness measurements. Geoderma 52, 235-250.

Nearing, M.A., 1998. Why soil erosion models over-predict small soil losses and under-predict large soil losses. Catena 32, 15-22.

Nearing, M.A., Govers, G., Norton, D.L., 1999. Variability in soil erosion data from replicated plots. Soil Sci. Soc. Am. J. 63, 1829-1835.

NOAA NCDC Climate Data Online 2011. Download 07/11. <http:// cdo.ncdc.noaa.gov/CDO/cdo>.

Onstad, C.A., 1984. Depressional storage on tilled soil surfaces. Trans. ASAE 27, 729732 .

R Development Core Team, 2007. R: A Language and Environment for Statistical Computing. <http://www.R-project.org>.

Schmidt, J., Von Werner, M., Michael, A., 1996. EROSION-2D/3D. Ein Computermodell zu Simulation der Bodenerosion durch Wasser. Sächsische Landesanstalt für Landwirtschaft/Sächsisches Landesamt für Umwelt und Geologie, Dresden/Freiberg, Germany.

Schramm, M., 1994. Ein Erosionsmodell mit räumlich und zeitlich veränderter Rillenmorphologie. Mitt. Inst. Wasserbau und Kulturtechnik Karlsruhe. 190. PhD thesis, TU Karlsruhe, Germany.

Schröder, R., Auerswald, K., 2000. Modellierung des Jahresgangs der verschlämmungsinduzierten Abflussbildung in kleinen landwirtschaftlich genutzten Einzugsgebieten. Z. Kulturtechnik Landentw. 41, 167-172.

Schwertmann, U., Vogl, W., Kainz, M., 1987. Bodenerosion durch Wasser - Vorhersage des Abtrags und Bewertung von Gegenmaßnahmen. Stuttgart, Germany.

Seibert, S., Auerswald, K., Fiener, P., Disse, M., Martin, W., Haider, J., Michael, A. Gerlinger, K., 2011. Surface runoff from arable land - a homogenized data base of 726 rainfall simulation experiments. doi: 10.1594/GFZ.TR32.2.

Silverman, B.W., 1986. Density Estimation for Statistics and Data Analysis. Chapman and Hall/CRC, London, UK. 
Sinowski, W., Auerswald, K., 1999. Using relief parameters in a discriminant analysis to stratify geological areas with different spatial variability of soil properties. Geoderma 89, 113-128.

Soil Survey Staff, 2010. Keys to Soil Taxonomy. USDA-Natural Resources Conservation Service, Washington, DC, USA

Swanson, N.P., 1965. Rotating-boom rainfall simulator. Trans. ASAE 8, 71-72.

Volf, C.A., Ontkean, G.R., Bennett, D.R., Chanasyk, D.S., Miller, J.J., 2007. Phosphorus losses in simulated rainfall from manured soils of Alberta. J. Environ. Qual. 36, 730-741.
Warren, S.D., Hohmann, M.G., Auerswald, K., Mitasova, H., 2004. An evaluation of methods to determine slope using digital elevation data. Catena 58, 215-233.

Wischmeier, W.H., Smith, D.D., 1960. A universal soil-loss equation to guide conservation farm planning. Trans. Int. Congr. Soil Sci. 7th. Madison, Wisc., pp. 418-425.

Wischmeier, W.H., Smith, D.D., Uhland, R.E., 1958. Evaluation of factors in the soilloss equation. Agric. Eng., 458-462. 